\title{
SARS-CoV-2 Infection and Diabetes
}

\author{
Federica Cavallo* and Francesco Chiarelli \\ Department of Paediatrics, University of Chieti, Italy
}

Submission: April 16, 2020; Published: May 04, 2020

*Corresponding author: Francesco Chiarelli, Department of Paediatrics, University of Chieti, Via dei Vestini, 5 - I-66100 Chieti, Italy

\begin{abstract}
The outbreak of severe acute respiratory infections is being one of the most serious risks to global health. In early December 2019, many pneumonia cases with unknown reason emerged in Wuhan, Hubei, China. Sequencing the samples from lower respiratory tract, scientists have revealed a novel coronavirus that was named 2019 novel coronavirus (SARS-CoV-2). The most common symptoms identified were: fever, dry cough and dyspnoea. Thus, doctors were concerned about the possibility that patients with cardiovascular disease, diabetes or other chronic diseases were more exposed to complications.

It is now well known that human pathogenic coronaviruses (severe acute respiratory syndrome coronavirus [SARS-CoV] and SARS-CoV-2) bind to their target cells through angiotensin-converting enzyme 2 (ACE2), which is expressed by the epithelial cells of the lung, intestine, kidney and blood vessels. The expression of ACE2 is mainly increased in patients with hypertension treated with ACE-inhibitors and in patients with diabetes. This could explain why these patients are more susceptible to the infection and its severe consequences, including death. Actually, current literature has shown a relation between metabolic comorbidities and a worse outcome for Covid-19 infection. The aim of this short report is to report the current knowledge on the relation between hyperglycaemia, diabetes and severity of SARS-CoV-2 infection.
\end{abstract}

Keywords: COVID-19; Diabetes; ACE2; Obesity; Hypertension; IL-6

Abbreviations: SARS-CoV-2: 2019 Novel Coronavirus; SARS-CoV: Severe Acute Respiratory Syndrome Coronavirus; ACE2: AngiotensinConverting Enzyme 2; ROS: Reactive Oxygen Species; IL-6: Interleukin-6

\section{Introduction}

In December 2019, several cases of respiratory infections in humans were reported in Wuhan, China [1]. The recognized pathogen was a novel virus, named "2019 novel coronavirus (SARS-CoV-2)" and was first isolated on 7 January 2020. Since then, the virus has spread worldwide and has infected 1914916 patients globally, causing 123010 deaths as of 15 April 2020 [2]. The SARS-CoV-2 is an enveloped, single-stranded RNA virus that can be transmitted from human to human through respiratory droplets [3]. Moreover, since SARS-CoV-2 RNA has been detected in the stool of some patients, faecal-oral transmission could be possible [4]. The phylogenetic analysis revealed that COVID-19 is potentially a zoonotic virus. According to the similarity of SARS-CoV-2 to bat SARS-CoV-like coronaviruses, it is likely that bats serve as reservoir hosts for its progenitor [3]. The most common symptoms at onset of COVID-19 disease are fever, cough and fatigue. Other symptoms include headache, haemoptysis, diarrhoea, dyspnoea. Older people and patients with pre-existing medical conditions such as high blood pressure, heart disease, lung disease, cancer and diabetes appear to develop serious illness more often than others [5].
Several investigations have demonstrated a higher susceptibility to some infectious diseases in patients with diabetes, probably because of a dysregulation of the immune system. In fact, diabetes is a multifactorial metabolic disease, characterized by insulin resistance, glucose intolerance and hyperglycaemia [6]. A recent study reported that the mortality rate of COVID-19 in patients with diabetes and without other comorbidities is about $16 \%$ [7]. Hence, we review the current clinical evidence of the correlation between diabetes and COVID-19 infection.

\section{Diabetes and Inflammation}

Nowadays it is well known that chronic hyperglycaemia accelerates the formation of advanced glycation end products and increased levels of free fatty acids and stimulates the production of inflammatory mediators and reactive oxygen species (ROS) [8]. It is proposed that systemic immune activation and pro-inflammatory cytokines are central to the development of micro- and macro-vascular complications associated to chronic hyperglycaemia, particularly in obese patients with type 2 diabetes [9]. In addition, the inflammation related to obesity is 
characterized by an increased activation of innate and adaptive immunity cells in adipose tissue with an increased release of inflammatory factors and chemokines locally and systemically [10].

Several studies on SARS-CoV showed that a known history of diabetes and an ambient hyperglycaemia, before any steroid therapy, are independent predictors of morbidity and mortality, due to the consequent inflammation and the hypoxia of the tissues. In this way, hyperglycaemia might reflect the multisystem involvement and underline the high risk of death among diabetic patients developing SARS [11]. More importantly, the normalization of blood glucose levels with the suppression of ketosis are able to reduce mortality and morbidity especially in diabetic patients [12].

Therefore, diabetes seems to worsen the outcome of viral infections as already happened with the 2003 severe acute respiratory syndrome due to SARS-CoV or the H1N1 infection. This seems to be the case also for patients affected by COVID-19. In fact, people with diabetes have a low grade of chronic inflammation that could facilitate the progression of the typical 'cytokine storm' that has been shown to be the cause of severe cases of COVID-19 infection [13]. Cytokine release syndrome is a systemic inflammatory response, which can be caused by infection, some drugs and other factors, characterized by a sharp increase in the level of a large number of pro-inflammatory cytokines [14]. A retrospective study in Wuhan has shown that among different markers of inflammation (C-reactive protein, fibrinogen, D-dimer), interleukin-6 (IL-6) seems to be the more represented in diabetic patients than in patients without diabetes [7].

The IL- 6 has a pleiotropic activity on inflammation and immunity. Usually, it induces the synthesis of acute phase proteins whereas it inhibits the production of albumin. Moreover, IL-6 stimulates the acquired immune response and promotes the proliferation of several non-immune cells [15]. Therefore, the increased synthesis of IL-6 could play a relevant effect and lead to the 'cytokine storm' associated with the COVID-19 infection. During this inflammatory storm, the D-dimer increases significantly. This iper-inflammation can also lead to an overall hypercoagulable state or even disseminated intravascular coagulation. The presence of higher level of D-dimer and fibrinogen and higher production of pro-inflammatory cytokines in patients with diabetes could indicate that they are also more inclined to present a hypercoagulable state than patients without diabetes. These data show that COVID-19 patients with diabetes are at higher risk of excessive uncontrolled inflammation responses and hypercoagulable state, which may contribute to poorer prognosis of COVID-19 [16].

\section{The Role of ACE-2 Receptor}

COVID-19, like others coronaviruses (SARS-CoV in 2003), uses a specific ACE2 receptor to invade cells, particularly type II pneumocytes. Many studies also confirm, through biophysical and structural analysis, that the 2019-nCoV S protein binds angiotensin-converting enzyme 2 (ACE2) with higher affinity than severe acute respiratory syndrome (SARS-CoV) $[17,18]$. It is well known that ACE-2 receptor can be found in lung, kidney, heart and also in the pancreatic islets. In some studies, it has been described that the severity of the disease and damage to several organs (lung, kidney, liver) is related to organ expression of ACE2. The localization of ACE2 in the endocrine part of the pancreas suggests that SARS-CoV enters islets using ACE2 as its receptor and may potentially cause acute hyperglycaemia and diabetes [19]. Therefore, it is possible to speculate that SARS-CoV2 could act in a similar way and worsen diabetes control in patients with diabetes or induce hyperglycaemia in non-diabetic patients.

Preliminary reports showed that hyperglycaemia may be present in more than $50 \%$ of patients with the novel COVID-19 infection [20]. Interestingly, previous studies on SARS-CoV in 2003, have demonstrated that hyperglycaemia is an independent predictor of death and sometimes diabetes have occurred during the course of SARS. Usually, hyperglycaemia has been transient [21]. These consequences could be explained by the fact that SARS-CoV and SARS-CoV2 can damage islets cells and reduce insulin production [22].

\section{Conclusions}

According to a retrospective study led to Wuhan, almost 20\% of the patients affected by COVID-19 had diabetes as underlying disease with poorer prognosis [23]. Another study, of about 150 patients ( 68 deaths and 82 recovered patients) in Wuhan, showed that the number of comorbidities is a significant predictor of mortality [24]. The most distinctive comorbidities of 32 nonsurvivors from a group of 52 intensive care unit patients with novel coronavirus disease 2019 (COVID-19) were cerebrovascular diseases (22\%) and diabetes (22\%) [25].

A report of 72,314 cases of COVID-19 published by the Chinese Centre for Disease Control and Prevention showed increased mortality in people with diabetes $(2.3 \%$, overall and $7.3 \%$, patients with diabetes) [26].

These data are important to define that an impairment of glucose metabolism may significantly affect the prognosis of COVID-19. In fact, these patients show a higher mortality rate, which further support the hypothesis that diabetes is a risk factor for the prognosis of COVID-19. It is possible that there is a one to one relationship between COVID-19 infection and diabetes due on the one hand to the chronic inflammation typical of the diabetic patient and on the other hand to the direct invasion of pancreatic islets by the virus. Further studies are needed to better understand the pathophysiological mechanism underlying this process. 


\section{Acknowledgements}

Federica Cavallo and Francesco Chiarelli participated in the literature search and manuscript writing. Francesco Chiarelli critically reviewed the manuscript.

\section{Declaration of Competing Interest}

The authors declare that they have no known competing financial interests or personal relationships that could have appeared to influence the work reported in this paper.

\section{References}

1. Lu H, Stratton CW, Tang YW (2020) Outbreak of pneumonia of unknown etiology in Wuhan China: The mystery and the miracle. J Med Virol 92(4): 401-402.

2. World Health Organization (2020) Coronavirus Disease 2019 (COVID-19): Situation Report. Geneva, Switzerland.

3. Andersen KG, Rambau A, Lipkin WI (2020) The proximal origin of SARS-CoV-2. Nature Med 26(4): 450-452.

4. Yeo C, Kaushal S, Yeo D (2020) Enteric involvement of coronaviruses: is faecal-oral transmission of SARS-CoV-2 possible? Lancet Gastroenterol Hepatol 5(4): 335-337.

5. Huang C, Wang Y, Li X, Ren L, Zhao J, et al. (2020) Clinical features of patients infected with 2019 novel coronavirus in Wuhan, China. Lancet 395(10223): 497-506.

6. Hodgson K, Morris J, Bridson T, Govan B, Rush C, Ketheesan N (2015) Immunological mechanisms contributing to the double burden of diabetes and intracellular bacterial infections. Immunology 144(2): 171-185.

7. Guo W, Li M, Dong Y, Zhou H, Zhang Z, et al. (2020) Diabetes is a risk factor for the progression and prognosis of COVID-19. Diabetes Metab Res Rev 31: e3319.

8. Vlassara H, Cai W, Crandall J (2002) Inflammatory mediators are induced by dietary glycotoxins, a major risk factor for diabetic angiopathy. Proc Natl Acad Sci U S A 99: 15596-15601.

9. Donath MY, Shoelson SE (2011) Type 2 diabetes as an inflammatory disease. Nat Rev Immunol 11: 98-107.

10. Meshkani R, Vakili S (2016) Tissue resident macrophages: Key players in the pathogenesis of type 2 diabetes and its complications. Clinica Chimica 462: 77-89.

11. Yang JK, Feng Y, Yuan MY, Yuan SY, Fu HJ, et al. (2006) Plasma glucose levels and diabetes are independent predictors for mortality and morbidity in patients with SARS. Diabet Med 23(6): 623-628.

12. Malmberg K, Ryden L, Hamsten A, Herlitz J, Waldenstrom A, Wedel $\mathrm{H}$ (1996) Effects of insulin treatment on cause-specific one-year mortality and morbidity in diabetic patients with acute myocardial infarction. DIGAMI Study Group. Diabetes Insulin-Glucose in Acute Myocardial Infarction. Eur Heart J 17(9): 1337-1344.
13. Mehta P, McAuley DF, Brown M, Sanchez E, Tattersall RST, Manson JJ (2020) COVID-19: consider cytokine storm syndromes and immunosuppression. Lancet 395: 1033-1034.

14. Zhang C, Wu Z, Li JW, Zhao H, Wang GQ (2020) The cytokine release syndrome (CRS) of severe COVID-19 and Interleukin-6 receptor (IL6R) antagonist tocilizumab may be the key to reduce the mortality. Int J Antimrob Agents 29: 105954.

15. Toshio T, Masashi N, Tadamitsu K (2014) IL-6 in inflammation, immunity and disease. Cold Spring Harb Perspect Biol 6: a016295.

16. Maddaloni E, Buzzetti R (2020) Covid-19 and diabetes mellitus: unveiling the interaction of two pandemics. Diabetes Metab Res Rev 31: e33213321.

17. Wan Y, Shang J, Graham R, Baric RS, Li F (2020) Receptor Recognition by the Novel Coronavirus from Wuhan: an analysis based on decadelong structural studies of SARS Coronavirus. J Virol 94: e00127-320.

18. Wrapp D, Wang N, Corbett KS, Goldsmith JA, Hsieh CL (2020) CryoEM structure of the 2019-nCoV spike in the prefusion conformation. Science 367(6483): 1260-1263.

19. Jin-Kui Y, Shan-Shan L, Xiu-Juan J, Li-Min G (2010) Binding of SARS coronavirus to its receptor damages islets and causes acute diabetes. Acta Diabetologica 47(3): 193-199.

20. Ilias I, Zabuliene L (2020) Hyperglycemia and the novel Covid-19 infection: Possible pathophysiologic mechanisms. Med Hypotheses 139: 109699 .

21. Yang JK, Lin SS, Ji XJ, Guo LM (2010) Binding of SARS coronavirus to its receptor damages islets and causes acute diabetes. Acta Diabetol 47(3): 193-199.

22. Bornstein SR, Dalan R, Hopkins D, Mingrone G, Boehm BO (2020) Endocrine and metabolic link to coronavirus infection. Nat Rev Endocrinol.

23. Wang D, Hu B, Hu C, Zhu F, Liu X, et al. (2020) Clinical Characteristics of 138 Hospitalized Patients With 2019 Novel Coronavirus-Infected Pneumonia in Wuhan, China. JAMA 323: 1061-1069.

24. Ruan Q Yang K, Wang W, Jiang L, Song J (2020) Clinical predictors of mortality due to COVID-19 based on an analysis of data of 150 patients from Wuhan, China. Intensive Care Med.

25. Yang X, Yu Y, Xu J, Shu H, Xia J, et al. (2020) Clinical course and outcomes of critically ill patients with SARS-CoV-2 pneumonia in Wuhan, China: a single-centered, retrospective, observational study. Lancet Respir Med 8(4): e26.

26. Wu Z, McGoogan JM (2020) Characteristics of and important lessons from the coronavirus disease 2019 (COVID-19) outbreak in China: summary of a report of 72314 cases from the Chinese center for disease control and prevention. J Am Med Assoc 323: 1239-1242. 
This work is licensed under Creative Commons Attribution 4.0 Licens

DOI: 10.19080/CRDOJ.2020.13.55586

Your next submission with Juniper Publishers will reach you the below assets

- Quality Editorial service

- Swift Peer Review

- Reprints availability

- E-prints Service

- Manuscript Podcast for convenient understanding

- Global attainment for your research

- Manuscript accessibility in different formats

( Pdf, E-pub, Full Text, Audio)

- Unceasing customer service

Track the below URL for one-step submission https://juniperpublishers.com/online-submission.php 